\section{Dose-response effects of ethanol on appetitive behaviors*}

\author{
FRANK A. HOLLOWAY \\ University of Oklahoma Medical Center, Oklahoma City, Okla. 73104 \\ and \\ DONALD R. VARDIMAN \\ The William Paterson College of New Jersey, Wayne, N.J. 07470
}

A dose-response analysis of systemic injections of ethanol on appetitive behaviors indicated that low doses facilitated responding in food-motivated fixed ratio and DRL tasks without parallel increases in food consumption or general activity. Higher doses of ethanol produced the expected depression of all behaviors examined. The results were discussed in terms of the possible differential sensitivity of different behavioral processes and/or brain areas to the effects of the drug.

Evidence available from behavioral (Eriksson \& Wallgren, 1967) and neurophysiological studies (Sauerland, Knauss, \& Clemente, 1967) indicate that low doses of ethanol enhance open-field activity and certain reflexes, while high doses tend to depress these measures. Although the precise locus and nature of ethanol's action on the nervous system is still not known, there have been remarkably few attempts to assess the generality of this kind of nonmonotonic dose response effect of ethanol on other kinds of behaviors or behavioral processes.

The present investigation examined the effects of different doses of ethanol on several kinds of appetitive behaviors. Experiment 1 examined dose-response effects of ethanol on operant responding for food reinforcement and on food consumption per se. Experiment 2 assessed the dose-response effects of ethanol on spontaneous activity and on those response-inhibitory/initiation processes necessary for efficient performance in a differential reinforcement of low rates of responding (DRL) task.

\section{EXPERIMENT 1}

Operant Performance

Twenty-four 120- to 150-day-old male Sprague-Dawley rats were trained by operant shaping procedures to press a lever for $45-\mathrm{mg}$ Noyes pellets in a standard Skinner box. Prior to and during all training sessions, all Ss were maintained on a food-deprivation regime which stabilized their weight at $80 \%$ of their average weight during the last 10-day predeprivation period. After the operant leverpress response was shaped, all Ss were given a sequence of 1 -h fixed-ratio (FR) schedules of reinforcement for leverpressing (FR 1, FR 5, FR 10,

*This investigation was supported in part by Public Health Service Grant 14702 from the National Institute of Mental Health.
FR 20, and FR 30). Animals were run on each schedule until their responding had stabilized. Operant performance under conditions of FR 10, FR 20, and/or FR 30 schedules of reinforcement was examined after intraperitoneal (IP) injections of $0.9 \%$ saline or $10 \%(w / v)$ ethanol-saline solutions. Fifteen minutes prior to each daily session, all Ss received injections of one of the following doses of the ethanol-saline $\left({ }^{*} \mathrm{p}<.05,{ }^{*} \mathrm{p}<.01\right)$. solution: $0.2,0.4,0.8,1.2$, or $1.6 \mathrm{~g}$ ethanol/kg body weight, or an equivalent volume of the saline solution. For a given ethanol dose and reinforcement schedule, all animals received a 3-day sequence of saline, ethanol, and saline injections. Not all animals received all schedules of reinforcement or all doses of ethanol. Food Consumption

In order to determine the effects of ethanol on food consumption per se, 24 Sprague-Dawley rats, maintained at $80 \%$ normal body weight, were given 1-h ad lib access to lab chow daily for a 10-day period. The amount of food consumed in $1 \mathrm{~h}$ was then examined for IP saline and saline-ethanol injections in four groups of animals $(N=6)$, each receiving one of the following doses of ethanol: $0.4,0.8$, 1.2 , or $1.6 \mathrm{~g} / \mathrm{kg}$ body weight.

Results

The top portion of Fig. 1 shows the mean differences in reinforcements obtained by operant responding between successive saline and ethanol injection sessions for each of the Schedule of Reinforcement by Drug Dosage interactions. The number of Ss in each of these treatment combinations ranged from a maximum

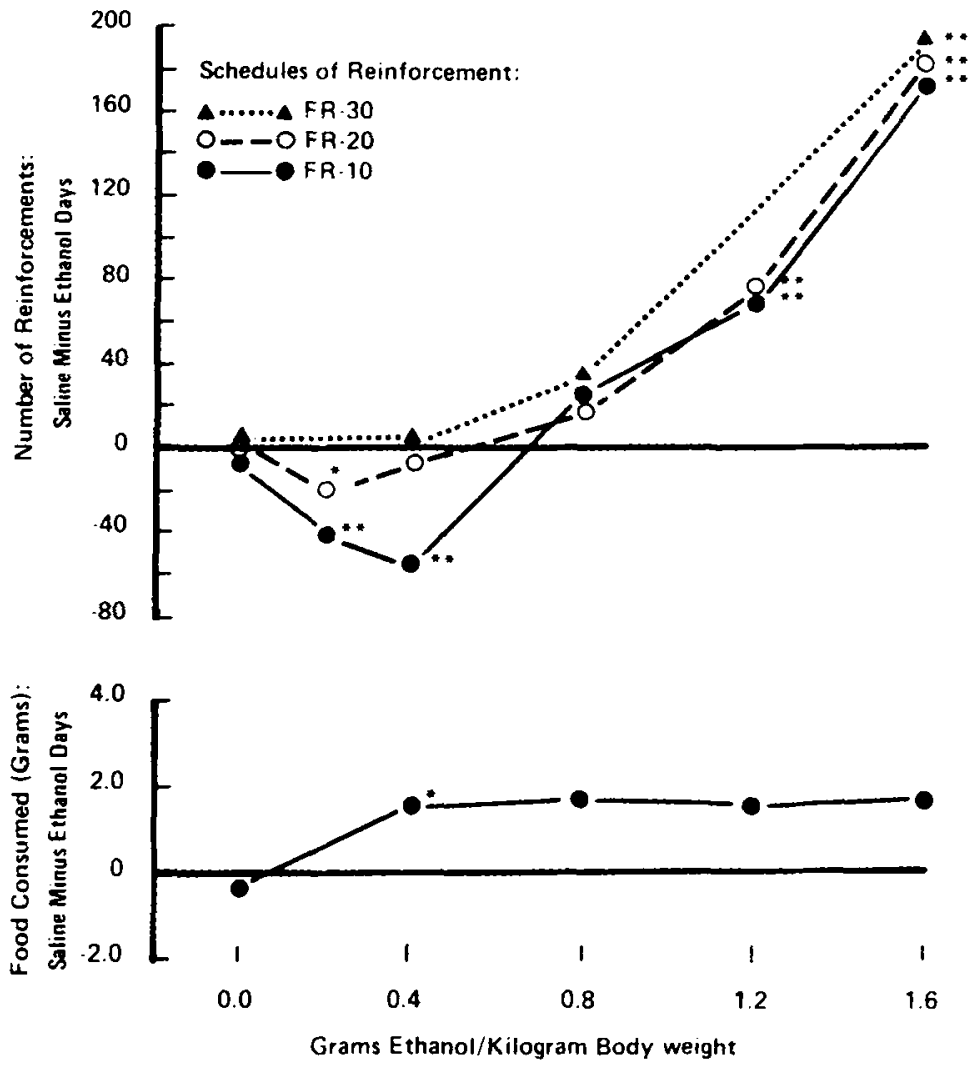

Fig. 1. Dose-response effects of ethanol on reinforcements obtained by operant responding (top) and on food consumption (bottom). Saline-ethanol differences were assessed with the Wilcoxon matched-pairs signed-rank test 

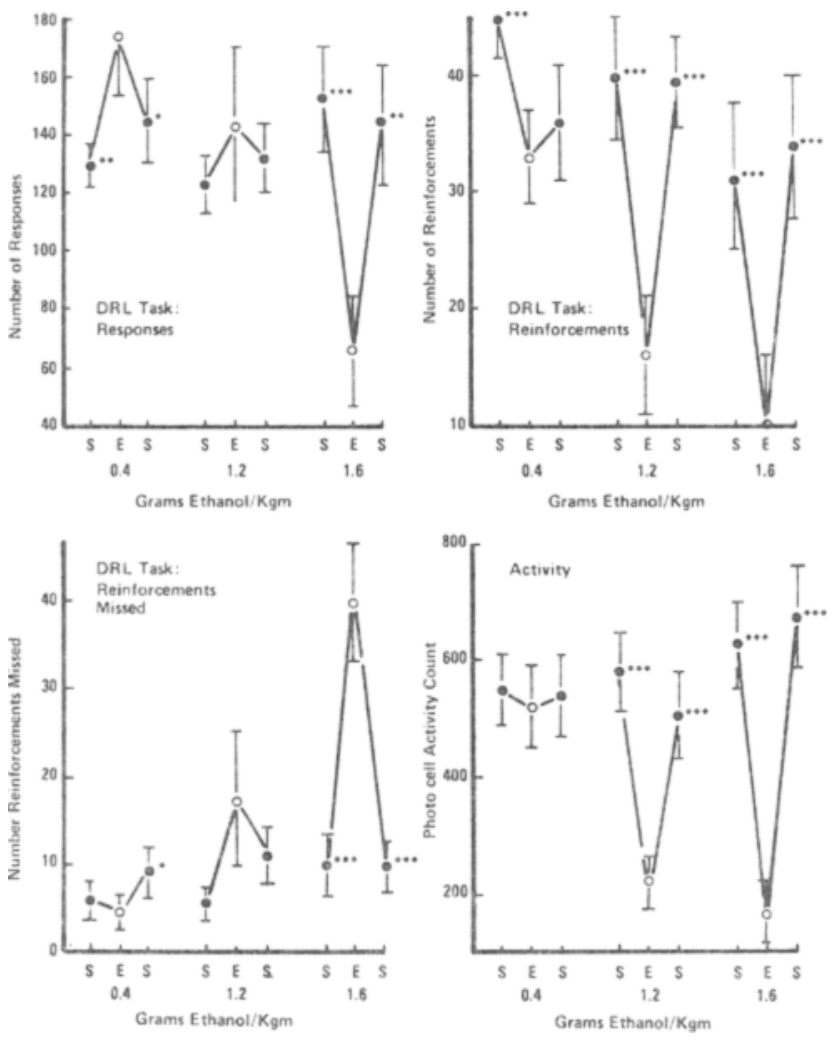

Fig. 2. Dose-response effects of ethanol on DRL 20 -sec limited hold 10 -sec performance and on spontaneous activity during saline (S) and ethanol (E) sessions. Saline-ethanol differences were assessed with the Wilcoxon matched-pairs signed rank test $\left({ }^{*} p<.10, * * p<.05, * * * p<.01\right)$.

of 15 to a minimum of 6 . The saline-ethanol differences in number of leverpresses (as indicated by number of reinforcements obtained) was tested with the Wilcoxon matched-pairs signed-ranks procedure. As can be seen in Fig. 1, the two lower doses of ethanol produced a significant increase in reinforcements, i.e., responding, at least for the $F R 10$ schedule of reinforcement. At higher dose levels $(0.8 \mathrm{~g} / \mathrm{kg}$ and above) responding, and hence reinforcements obtained, decreased monotonically as dosage increased. The low dose facilitatory effect of ethanol on responding appears to be a rather subtle effect, being manifest at less demanding schedules (FR 10) and absent at more demanding (FR 30) schedules of reinforcement.

The bottom portion of Fig. 1 shows the dose-response effects of ethanol on food consumption. These data indicated that all doses of the drug resulted in a decrease in amount of food consumed, but this effect was significant only at the lowest dose level.

Discussion

The results of Experiment 1 provided information concerning the dose-response characteristics of ethanol in a food-reinforced operant task. The apparent facilitatory effect of low doses of ethanol on operant responding could have been due to ethanol's effect on any of several processes: (1) primary hunger "drive" or motivational processes related to food deprivation, (2) general activity or activation level of the organism, (3) motor mechanisms requisite for performance, or (4) response-inhibitory processes. The first alternative was apparently ruled out by the failure to find changes in food consumption which paralleled the dose-response characteristics of the operant behaviors.

\section{EXPERIMENT 2}

DRL Performance

Thirty 130 - to 160-day-old male Sprague-Dawley rats were Ss in the present experiment. They were all trained to leverpress for food reinforcement and were maintained at $80 \%$ of their basal body weights (as in Experiment 1). All Ss were trained on a DRL 20-sec task, where reinforcement was available on the first leverpress $20 \mathrm{sec}$ after the last response, until a criterion of five or fewer responses for every reinforcement was attained. The session duration was always $30 \mathrm{~min}$. After the DRL $20-\mathrm{sec}$ schedule criterion performance was met, each animal was shifted to a limited-hold variation of the latter schedule, in which the animal was reinforced for the first response occurring at least $20 \mathrm{sec}$ after its previous response, but only had a 10-sec window in which reinforcement was available. If the $S$ did not respond within the 10 -sec window, it had to wait another $20 \mathrm{sec}$ before another $10-\mathrm{sec}$ reinforcement period would become available.

After criterion performance was attained on the DRL 20-sec limited-hold $10 \mathrm{sec}$ schedule, all animals began a 3 -day series of saline, ethanol, saline injection sessions. Each of three groups of Ss $(10$ animals/group) received $\mathbf{P}$ injections of saline and one of the following doses of ethanol $15 \mathrm{~min}$ before each experimental session: $0.4,1.2$, or $1.6 \mathrm{~g}$ ethanol/kg body weight. The number of leverpresses, number of reinforcements obtained, and number of reinforcement opportunities missed were recorded for the $30-\mathrm{min}$ period. Activity

After the termination of the DRL tasks, each group of animals was given another 3-day series of IP saline, ethanol, saline injections in which activity in a darkened standard activity chamber (chamber diam $=24$ in.) was recorded during a 30-min period. Each group received the same dose of ethanol as it had received during the DRL task.

\section{Results}

The means and standard errors for DRL performance and activity with saline and each of the dose levels of ethanol are presented in Fig. 2. As can be seen in the figure, the low ethanol dose did not significantly alter spontaneous activity but did significantly increase the number of responses during the $30-\mathrm{min}$ session. The increase in responding in this group resulted in significantly fewer reinforcements, but the animals showed no change in number of reinforcement opportunities missed. The middle dose level resulted in the same pattern of performance on the DRL task but significantly less spontaneous activity. The highest dose level employed resulted in a significant suppression of spontaneous activity, of number of leverpresses, and of number of reinforcements. The overall depression of behaviors with the high dose is further reflected in the significant increase in reinforcement opportunities missed.

The results of Experiment 2 indicate that low doses of ethanol impaired DRL performance, as 
measured by the number of reinforcements obtained in a fixed amount of time, by increasing the number of inappropriate responses. The high dose of ethanol, on the other hand, impaired DRL performance by suppressing operant responding to the point that reinforcement opportunities were missed. The fact that the low ethanol dose level did not increase spontaneous activity suggests that the number of operant responses cannot be attributed to any generalized excitatory effects of the drug but rather to more specific behavioral effects involving suppression of response-inhibitory mechanisms.

\section{GENERAL DISCUSSION}

The findings of the present investigation are consistent with those of Eriksson \& Wallgren (1967) and Sauerland et al (1967), in which ethanol was shown to have a facilitatory effect on certain behaviors or reflexes at low dose levels and a depressant effect on these and other phenomena at higher dose levels. The low-dose facilitatory effect on food-motivated operant behaviors found in the present study apparently was not related to changes in primary hunger mechanisms per se or to changes in general activity levels, but rather to a more selective effect on mechanisms involving response inhibition.

Eriksson \& Wallgren's (1967) finding in rats and Arvola's (1960) finding in mice that low doses of ethanol increased ambulation scores in an open field is consistent with a disinhibition hypothesis, since these behaviors are normally suppressed. Sauerland et al (1967) actually found a blockage of nominal frontal lobe inhibition on several types of reflexes at a dose of ethanol low enough not to affect the magnitude of the reflex proper. This finding, of course, suggests that those brain areas (i.e., frontal cortex) having inhibitory control over certain reflexes are more sensitive to the effects of ethanol than are those brain areas responsible for the nominal production of the reflex. Wayner (1970) cites evidence showing that extremely small doses of ethanol injected systemically into rats increases the spontaneous discharge rate of sodium-sensitive lateral hypothalamic neurons. Whether this finding is related to the low-dose "disinhibitory effects" of the drug on operant behaviors in the present study or on cortically induced reflex inhibition (Sauerland et al, 1967) is not clear at the present time.

The finding, however, that low-dose facilitatory effect of ethanol can be shown for certain types of operant behaviors suggests that future research should carefully examine the effects of chronic injections of ethand on those behavioral parameters which are facilitated by low-dose acute injections of the drug. If it is true that ethanol differentially affects certain brain areas or behavioral processes, then it seems plausible that with long-term exposure to the drug, these behaviors or brain mechanisms may display a progressive and more rapid deterioration than other behaviors or brain mechanisms, due to their differential sensitivity to ethanol.

\section{REFERENCES}

ARVOLA, A. A method for recording general activity of mice. Acta Physiologica Scandinavica, 1960,49, 62-64.

ERIKSSON, K., \& WALLGREN, H. Behaviour of rats under the influence of ethyl alcohol in an open field situation. Scandinavian Journal of Psychology. $1967,8,257-267$.

SAUERLAND, E. K., KNAUSS, T., \& CLEMENTE, C. D. Effects of ethyl alcohol on orbital-cortically induced reflex inhibition in the cat. Brain Research, 1967, 6, 164-180.

WAY NER, M. J. Motor control functions of the Lateral hypothalamus and adjunctive behavior. Physiology \& Behavior, 1970. 5, 1319-1325.

\section{CURRENT LITERATURE ON ANIMAL MOTTVATION}

AVIS, H. H. (Research Laboratories, Edgewood Arsenal, Md. 21010), \& TREADWAY, J. T. Mediation of rat-mouse interspecific aggression by cage odor. Psychonomic Science, 1971, 22, 293-294.

DEAUX, E. (Antioch College, Yellow Springs, Ohio 45387), \& KAKOLEWSKI, J. W. Stress induced osmotic changes as a function of deprivation state. Psychonomic Science, 1971, 22, 171-172.

DEWSBURY, D. A. (University of Florida, Gainesville, Fla. 32601). Copulatory behavior of male rats following reserpine administration. Psychonomic Science, 1971, 22, 177-179.

DUTCH, J. (Victoria University of Wellington, Wellington, New Zealand), \& BROWN, L. B. Visual stimulus complexity and approach behavior in rats. Psychonomic Science, 1971, 22, 162-163.

ELIAS, M. F. (Duke University Medical Center, Durham, N.C. 27706), \& SIMMERMAN, S. J. Strain differences in memory and incentive as a function of external stimulation. Psychonomic Science, 1971, 22, 189-191.

FITTINGHOFF, N. A., JR. (Department of Anthropology,
University of California, Davis, Calif. 95616), LINDBURG, D. G., \& MITCHELL, G. Failure to find polydipsia in isolation-reared monkeys. Psychonomic Science, $1971,22,277-278$.

JENNINGS, W. A. (Howard University, Washington, D.C. 20001). Total home-cage activity as a function of the estrous cycle and wheel running in the rat. Psychonomic Science, 1971, 22, 164-165.

KNUTSON, J. F. (University of Iowa, Iowa City, lowa 52240). The effects of shocking one member of a pair of rats. Psychonomic Science, 1971, 22, 265-266.

LEVISON, C. A. (University of Chicago, Chicago, Ill. 60637), \& LEVISON, P. K. Effects of early visual conditions on stimulation-seeking behavior in young rhesus monkeys, II. Psychonomic Science, 1971, 22, 145-147.

McLEAN, J. H. (Louisiana State University in New Orleans, New Orleans, La. 70112), \& COLEMAN, W. P. Temperature variation during the estrous cycle: Active vs restricted rats. Psychonomic Science, 1971, 22, 179-180.

RASBURY, W. (Bowling Green State
University, Bowling Green, Ohio 43402), \& SHEMBERG, K. The effects of aversive levels of white noise on consummatory behavior. Psychonomic Science, 1971, 22, 166-167.

RUSKIN, R. S., \& GOODMAN, I. J. (West Virginia University, Morgantown, W. Va. 26505). Changes in locomotor activity following basal forebrain lesions in the pigeon. Psychonomic Science, $1971,22,181-183$.

SCLAFANI, A., \& GROSSMAN, S. P. (University of Chicago, Ill. 60637). Reactivity of hyperphagic and normal rats to quinine and electric shock. Journal of Comparative and Physiological Psychology, 1971, 74, 157-166.

TAYLOR, G. T. (University of New Mexico, Albuquerque, $N$. Mex. 87106). The incentive value of complexity. Psychonomic Science, $1971,22,143-144$.

WONG, P. T. P. (University of Texas at Austin, Austin, Tex. 78712), \& AMSEL, A. The effect of food deprivation and imprinting on the behavior of young domestic chicks. Psychonomic Science, 1971, 22, 169-170. 